\title{
"Alistando-se no invencível exército da página impressa" - Cultura impressa adventista no Brasil no século XX
}

\author{
Karina Kosicki Bellotti*
}

\section{RESUMO}

A mídia impressa foi fundamental para a expansão da Igreja Adventista do Sétimo Dia, por isso, refletimos sobre as representaçóes acerca da cultura impressa, que destacaram seus poderes de influência, instrução e evangelização, com auxílio do colportor. Partimos de referenciais teóricos sobre cultura impressa religiosa e representação para analisar a importância conferida pela igreja aos impressos e aos colportores no século XX. O estudo aponta para a noção de um potencial transformador da "boa" cultura impressa religiosa, como antídoto para a mídia secular supostamente propagadora de pecados.

Palavras-chave: mídia impressa religiosa; Igreja Adventista do Sétimo Dia; colportagem; cultura impressa; periódicos.

\section{"Enlisting in the invincible army of the printed page" - Adventist print culture in 20th-Century Brazil}

\section{ABSTRACT}

Print media was fundamental for the expansion of the Seventh-Day Adventist Church, therefore, it is important to reflect on representations related to print culture, which highlighted their powers of influence, instruction, and evangelization, with the help of colporteurs. This article uses theoretical references about religious print culture and representation to analyze the importance given by the church to printed material and colporteurs during the twentieth century. The study points to the notion that "good" religious print culture has transformative potential as an antidote to the secular media that supposedly propagates sins. Keywords: religious print media; Seventh-day Adventist Church; colportage; print culture; periodicals.

DOI: http://dx.doi.org/10.1590/2237-101X02204813

Artigo recebido em 7 de maio de 2020 e aceito para publicação em 9 de novembro de 2020.

* Professora da Universidade Federal do Paraná / Departamento de História, Curitiba/PR - Brasil. E-mail: karinakbellotti@gmail.com. ORCID: https://orcid.org/0000-0002-5353-8432. 


\section{“Alistándose en el increíble ejército de la página impresa” - Cultura impresa adventista en Brasil en el siglo XX}

\section{RESUMEN}

Los medios de comunicación impresos fueron fundamentales para la expansión de la Iglesia Adventista del Séptimo Día, por eso, reflexionamos sobre las representaciones acerca de la cultura impresa, que destacaron sus poderes de influencia, instrucción y evangelización, con ayuda del colportor. Partimos de referencias teóricos sobre la cultura impresa religiosa y la representación para analizar la importancia conferida por la iglesia a los colportores en el siglo XX. El estudio apunta para la noción de un potencial transformador de la "buena" cultura impresa religiosa, como antídoto para los medios de comunicación seculares, supuestamente propaganda de pecados.

Palabras Clave: medios de comunicación impresos religiosos; Iglesia Adventista del Sétimo Día; colportaje; cultura impresa; periódicos.

\section{Introdução}

O tema deste artigo é a cultura impressa adventista no século XX. Exploramos a relação da doutrina da igreja e sua inserção social com a importância que ela confere à leitura e à distribuição individual de leitura, feita por meio da colportagem - venda de porta em porta realizada por membros da Igreja Adventista do Sétimo Dia (IASD). A mídia impressa desempenhou papel fundamental na expansão da igreja desde o seu início nos Estados Unidos, em 1863, incluindo sua vinda ao Brasil, no final do século XIX.

A partir deste estudo de caso desenvolvemos reflexóes sobre as formas como a literatura foi representada na imprensa adventista, visto que livros, folhetos e tratados foram retratados com características próprias, quase humanas, com poder de influência na vida dos leitores, em um contexto de expansão dos primeiros meios de comunicação de massa. A leitura não era em si uma virtude - em um período de popularização de romances baratos e imprensa sensacionalista, era necessário ler a "boa literatura", saudável para a alma. Mas para que essa leitura chegasse ao povo, o trabalho dos colportores era visto como imperativo para concretizar o trabalho que Deus teria legado aos adventistas para difundir sua verdade. Apesar da existência das mídias digitais atualmente, a venda de literatura ainda é valorizada por igrejas como a Adventista do Sétimo Dia, pois no contexto atual ela serviria como o antídoto contra a solidão e a impessoalidade nas relaçóes sociais, além de sustentar a produção editorial da igreja. Partimos do conceito de representação conforme Roger Chartier (2002, p. 61-79) para analisar a cultura impressa adventista, e os referenciais teóricos da história da leitura e da cultura impressa religiosa de Roger Chartier, e Paul Boyer e Charles Cohen (2008), 
“AlisTANDO-SE NO INVENCÍVEL EXÉRCITO DA PÁGINA IMPRESSA" - CULTURA IMPRESSA ADVENTISTA NO BRASIL NO SÉCULO XX

Karina Kosicki Bellotti

abarcando as suas formas de distribuição, os significados de sua partilha e as representaçôes sobre os impressos e a leitura.

Analisamos duas fontes produzidas pela IASD: primeiro, a Revista Adventista ${ }^{1}$, publicada pela Casa Publicadora Brasileira (CPB, editora da IASD), direcionada aos membros da igreja. Antes de ser intitulada como tal em 1931, essa revista teve outros nomes - Revista Trimensal (publicação trimestral, de 1906 a 1908) e Revista Mensal (1908 a 1931). Nesse periódico analisamos as representaçóes que lideranças e membros da IASD, brasileiros e estrangeiros, fizeram sobre o poder da mídia impressa, da colportagem e da leitura, em artigos que almejavam engajar os fiéis nessa atividade. Outra fonte é a revista Vida e Saúde, também editada pela CPB desde 1939, da qual analisamos propagandas dos anos 1930 a 1950 de impressos vendidos por colportagem, visando a um público não pertencente à igreja. Esses materiais permitem trabalhar com as representaçôes que a igreja realizou em relação às suas literaturas e aos seus distribuidores, explorando os sentidos que a leitura e o veículo impresso adquiriram na IASD, que mirava os públicos adventista e não adventista.

A mídia impressa foi importante para a inserção social de outras denominaçôes protestantes no Brasil desde meados do século XIX. Mesmo com a introdução de novos meios de comunicação (rádio, televisão, mídias digitais), os impressos possuem uma longevidade e uma autoridade entre suas instituiçóes e seus membros. Em parte, isso se deve à própria autoridade conferida à palavra escrita desde o início da Reforma Protestante, que considerou a Bíblia como único testemunho divino revelado a ser consultado pelos seres humanos. Posteriormente à Reforma, os impressos tornaram-se meio de evangelização e de difusão religiosa em uma lógica missionária ocidental que se popularizou no século XIX, quando os missionários protestantes americanos e europeus começaram a atuar no Brasil (MENDONÇA, 1995).

Os adventistas chegam ao nosso país no final do século XIX e também valorizam os impressos como meio de difusão e de legitimação social. Ao discutirmos a relaçáo das visões sobre leitura e a influência da literatura cultivadas pelos adventistas com as doutrinas e as estratégias de expansão da igreja, também analisamos como isso repercute em um imaginário que atribui aos meios de comunicação um poder de elevar ou desgraçar as mentes.

O texto se divide em duas partes - a primeira é sobre a relação da cultura impressa com os primórdios da Igreja Adventista do Sétimo Dia nos Estados Unidos e no Brasil, e as representaçôes sobre impressos na revista Vida e Saúde e na Revista Adventista, dos anos 1900 aos 1950, destacando as qualidades associadas aos impressos e à leitura. A segunda parte investiga as representaçóes narrativas e imagéticas sobre a colportagem, os colportores e as colportoras na Revista Adventista de 1906 a 1999. Os impressos continuam a ser valorizados

\footnotetext{
${ }^{1}$ Todos os materiais referenciados da Revista Adventista estáo digitalizadas e disponíveis para consulta gratuita na internet, no site: https://acervo.cpb.com.br/ra. Acesso em: 22 abr. 2020. Já os materiais da revista Vida e Saúde foram consultados no Centro de Memória Ellen G. White, da Universidade Adventista de São Paulo, no campus Engenheiro Coelho-SP.
} 
“Alistando-SE No INVENCÍvel EXÉRCito DA PÁGINA IMPRESSA" - Cultura IMPRESSA ADVENTISTA No Brasil No SÉCULO XX

Karina Kosicki Bellotti

pelos adventistas atualmente, porém, a união entre a mídia impressa e os meios digitais merece outro estudo. Por isso, nosso recorte cronológico termina com o final do século XX, que também coincide com o início da popularização das mídias digitais no Brasil.

\section{"A boa leitura robustece a mente" - a cultura impressa da Igreja Adventista do Sétimo Dia}

A cultura impressa se refere à forma como materiais impressos são produzidos, divulgados, vendidos, lidos; e como se relacionam com outros impressos, num contexto de circulação social. Roger Chartier (1989, p. 1-2) apontou para uma dupla definição de cultura impressa como processo social: a primeira trata-se de uma profunda transformação da vida pública e privada, espiritual e material trazida pela descoberta de novas técnicas de reprodução de textos, em especial no Hemisfério Norte no período moderno; a segunda (relacionada diretamente com o tema deste artigo) trata-se do conjunto de novos usos pedagógicos, religiosos, rituais, cívicos, dentre outros, que surgem da produçáo em massa de escrita e imagens.

Cohen e Boyer (2008) analisaram a cultura impressa religiosa considerando um mercado de impressos religiosos que se consolidou nos Estados Unidos a partir do século XIX, no qual grupos religiosos competiam pelo consumo e pela evangelização de seu público. Seu incremento deu-se pela queda nos preços do papel e das tecnologias de impressão, além do crescimento do engajamento religioso, em especial protestante, no missionarismo e na criação de novas denominaçôes (COHEN; BOYER, 2008).

Nesse contexto, além de fazer evangelização, os protestantes engajaram-se nos Estados Unidos para influenciar a cultura nacional através da difusão de impressos, que era até o início do século XX o maior meio de comunicação de massas (SMITH, 2015). No Brasil, ainda que não houvesse alto nível de alfabetização, a mídia impressa foi amplamente utilizada por igrejas protestantes ${ }^{2}$ desde que chegaram ao país, em meados do século XIX. Os trabalhos de Micheline Reinoux de Vasconcelos (2010) e Carlos Barros Gonçalves (2020) são exemplos de análises relevantes sobre a incorporaçáo da mídia impressa pelos protestantes no Brasil. A presença de mídias impressas visava atingir o público de classe média e de elite no Brasil, e promover o letramento das camadas mais pobres, pois uma das estratégias de inserção protestante no Brasil foi a construção de escolas, para que os analfabetos pudessem aprender a ler, dentre outras coisas, a Bíblia.

Foi pela distribuiçáo de literatura adventista que essa denominaçáo teria iniciado suas atividades no Brasil (SCHUNEMANN, 2002), entre comunidades de imigrantes alemães

\footnotetext{
${ }^{2}$ Segundo censo de 1890 , a população autodeclarada protestante foi de $1 \%$ - a de católicos era 99,7\%, enquanto no censo de 1940 foi de $2,6 \%$ e a de católicos foi de $95,2 \%$ - uma porcentagem que só cresceu a partir dos anos 1980, chegando aos $22,2 \%$ de 2010, com declínio acentuado de católicos (64,6\% da população) e crescimento de outras religióes, sem religião e ateus (CAMPOS, 2008, p. 9-47).
} 
“AlisTANDO-SE NO INVENCÍVEL EXÉRCITO DA PÁGINA IMPRESSA" - CULTURA IMPRESSA ADVENTISTA NO BRASIL NO SÉCULO XX

Karina Kosicki Bellotti

no Sul nos anos 1880, suscitando a vinda de missionários estadunidenses nos anos 1890. A Igreja Adventista do Sétimo Dia é uma denominação cristã criada nos Estados Unidos em 1863, e que se diferencia de outras igrejas cristâs pela defesa da guarda do sábado e, não do domingo, como dia santo. Os adventistas surgem do movimento millerita ${ }^{3}$, que aguardava o retorno de Jesus Cristo para 1844, e que se reagrupa após o denominado Grande Desapontamento (LAND, 2005), quando Jesus não retorna à Terra na data esperada. Seguindo a tradição milenarista cristã (DELUMEAU, 1997), os adventistas projetam para um futuro indeterminado a expectativa para o retorno de Cristo, e enxergam em seu presente a realização do Tempo do Fim - isto é, o período que anuncia o Juízo ou Julgamento Final, em que Cristo retornaria para derrotar o diabo e iniciar um reinado de mil anos, segundo as profecias do livro de Apocalipse.

Além disso, a igreja possui dentre suas figuras centrais Ellen Gould White (1827-1915), que desde os anos 1850 alegou ter visóes proféticas, que formaram boa parte da base doutrinária da denominação, juntamente com a Bíblia. As mensagens da escritora foram publicadas em diversos formatos, desempenhando importante papel de agregar uma comunidade de leitores que havia se engajado anteriormente no movimento millerita. Ainda que estudos como o de Mendonça e Velasques Filho (2002) não considerem os adventistas como um grupo protestante, a igreja se autodenomina como tal em seus canais oficiais ${ }^{4}$. Dentro do campo protestante, os adventistas enfrentam objeçôes de outras igrejas cristâs, por causa do sabatismo e da ênfase nos escritos proféticos de Ellen G. White em suas doutrinas, o que interfere na estratégia missionária adventista.

A atividade missionária adventista baseia-se na crença de que todas as pessoas devem conhecer a "verdade", isto é, a mensagem bíblica e as profecias de Ellen G. White, antes da iminente segunda vinda de Jesus Cristo (MORGAN, 1999). Assim, os sujeitos teriam condiçôes de se arrepender de seus pecados e entregarem sua vida a Jesus. A distribuição de literatura e de folhetos foi um dos principais veículos de divulgação da igreja desde seu início nos Estados Unidos, segundo David Morgan (1999), ganhando um sentido de urgência frente à tarefa de alertar o maior número possível de pessoas para o fim dos tempos, que era percebido como iminente na segunda metade do século XIX.

A denominação chegou ao Brasil seguindo movimento missionário adventista, que saiu dos Estados Unidos para outras partes do mundo (OLIVEIRA FILHO, 2004, p. 157-179). A primeira igreja adventista no Brasil foi fundada em Gaspar Alto, Santa Catarina, em 1896. Em 1900, na cidade do Rio de Janeiro, os adventistas fundaram a Casa Publicadora Brasileira, que produz materiais para os membros da igreja e para público não adventista. Em 1907

\footnotetext{
${ }^{3} \mathrm{O}$ movimento millerita foi nomeado por causa do seu líder, William Miller (1792-1849), que reuniu pessoas esperançosas pela segunda vinda de Cristo, calculada segundo a interpretação do livro de Daniel e do livro de Apocalipse para 22 de outubro de 1844 (LAND, 2005).

${ }^{4}$ QUEM SÃO OS ADVENTISTAS. Portal Adventistas. Disponível em: https://www.adventistas.org/pt/ institucional/os-adventistas/quem-sao-os-adventistas/. Acesso em: 29 abr. 2020.
} 
“AlisTANDO-SE NO INVENCÍVEL EXÉRCITO DA PÁGINA IMPRESSA" - CULTURA IMPRESSA ADVENTISTA NO BRASIL NO SÉCULO XX

Karina Kosicki Bellotti

estabeleceu sua sede em São Bernardo do Campo, em região que posteriormente passou a ser de Santo André-SP. Desde 1985, a sede está na cidade de Tatuí-SP (BORGES, 2000). Os polos difusores da mídia impressa têm sido os núcleos missionários adventistas surgidos em todas as regióes do país, fornecendo materiais aos colportores.

Desde 1906 a CPB editou a Revista Trimensal, que posteriormente veio a ser nomeada Revista Mensal (em 1908) e Revista Adventista (em 1931), o órgão oficial da IASD para seus fiéis. A publicação de revistas foi acompanhada pela venda de folhetos e livros sobre diferentes temas: saúde, nutrição, educação, profecias, maternidade, criação de filhos, casamento, que serviam de cartão de visitas para um interesse futuro no adventismo. A estratégia era atrair pessoas com leituras e açóes que demonstravam o quanto a igreja pretendia melhorar a vida dos sujeitos em diversos sentidos, sem demonstrar proselitismo num primeiro contato, para náo causar espanto ou rejeição no público. Dado o longo recorte de tempo deste artigo, não é possível detalhar os valores de assinatura e de compra de livros e revistas, mas observamos que, os preços anuais de assinatura e dos livros nem sempre eram compatíveis com os ganhos de um salário mínimo ${ }^{5}$, sendo mais acessíveis a um público de classe média e alta. Além disso, havia livros que eram verdadeiros investimentos, como os de saúde, tal como O conselheiro médico da familia (SWARTOUT, 1942), de capa dura, com muitas páginas e ilustraçôes, que eram vendidos como enciclopédias para serem consultadas e passadas de geração a geração.

O conceito de representação de Roger Chartier (2002, p. 61-79) nos auxilia na análise, pois grupos sociais elaboram suas representaçóes sociais para dar sentido à sua realidade, estabelecendo narrativas para sua vivência, além de limites identitários para grupos considerados diferentes. Na mídia religiosa, podemos verificar uma profusão de representaçôes sobre como um determinado grupo vê a si próprio, e como ele gostaria que outros grupos ou os seus próprios fiéis os vissem. Quem decide qual representação é válida ou não em geral é quem exerce poder dentro do grupo social. Portanto, no caso que analisamos, lideranças da IASD elaboraram tais representaçôes sobre os impressos, os leitores e os colportores, seguindo parâmetros da igreja norte-americana, visto que muitos dos colaboradores dos periódicos adventistas até meados do século XX eram missionários norte-americanos.

A Igreja Adventista do Sétimo Dia traz em seus impressos, tanto nos Estados Unidos quanto no Brasil, um imaginário racionalista, em que o conhecimento das ciências naturais e do corpo humano iluminaria a boa saúde e o bom viver (WHITE, 2013). O aprendizado do conhecimento científico e o cultivo da leitura têm sido valorizados pela igreja desde seus

\footnotetext{
${ }^{5}$ Por exemplo, a assinatura anual de Vida e Saúde em julho de 1940, mês da instituição do salário mínimo (240 mil réis), era de 18 mil réis, e seu valor unitário era de 1.500 réis; em agosto de 1956, o salário mínimo era de Cr\$3.800, enquanto a assinatura anual de Vida e Saúde era de Cr\$ 75,00, e valor unitário era de Cr\$ 7,00. A revista Vida e Saúde só passou a publicar sua tiragem de maneira intermitente a partir dos anos 1960, firmando a prática somente nos anos 1990, variando de 300 mil nos anos de maior tiragem a cerca de 40 mil nos anos de menor tiragem (meados dos anos 1990) (Dados sobre salário mínimo - AUDTEC, 2020).
} 
“Alistando-SE No INVENCÍvel EXÉrCito da PÁGINA IMPRESSA" - Cultura IMPRESSA ADVENTISTA No BRASIL No SÉCULO XX

Karina Kosicki Bellotti

primórdios. Dessa forma, a insígnia da Casa Publicadora Brasileira na primeira metade do século XX apresenta um livro aberto que ilumina - por meio da luz de uma vela - o mapa do Brasil (Figura 1). Tal figura pode levar a crer que se trata de uma Bíblia que traz luz ao país - contudo, a pequena insígnia não permite distinguir que tipo de livro seria esse.

Outra referência à representação da literatura como esclarecedora e civilizadora encontra-se na Figura 2, uma das representaçóes visuais mais marcantes deste ideal da literatura adventista, referente à propaganda do livro $A$ ciência do bom viver, em que uma família nuclear - pai, máe e dois filhos - contempla do portáo de sua casa o livro que irradia como o sol. A família, que será uma das protagonistas das propagandas de livro da CPB, é sempre branca, e nas revistas dos anos 1930 a 1960, obedecem à estética do American Way of Life, demonstrando os laços com a matriz norte-americana. Também não é muito diferente da estética apresentada na mídia secular no Brasil, em que predominam pessoas brancas nos mais diferentes veículos até os dias atuais (RAMOS, 2002).

Figuras 1 e 2 - Insígnia da Casa Publicadora Brasileira (1942, p. 24) e propaganda de A ciência do bom viver (1955, p. 24)
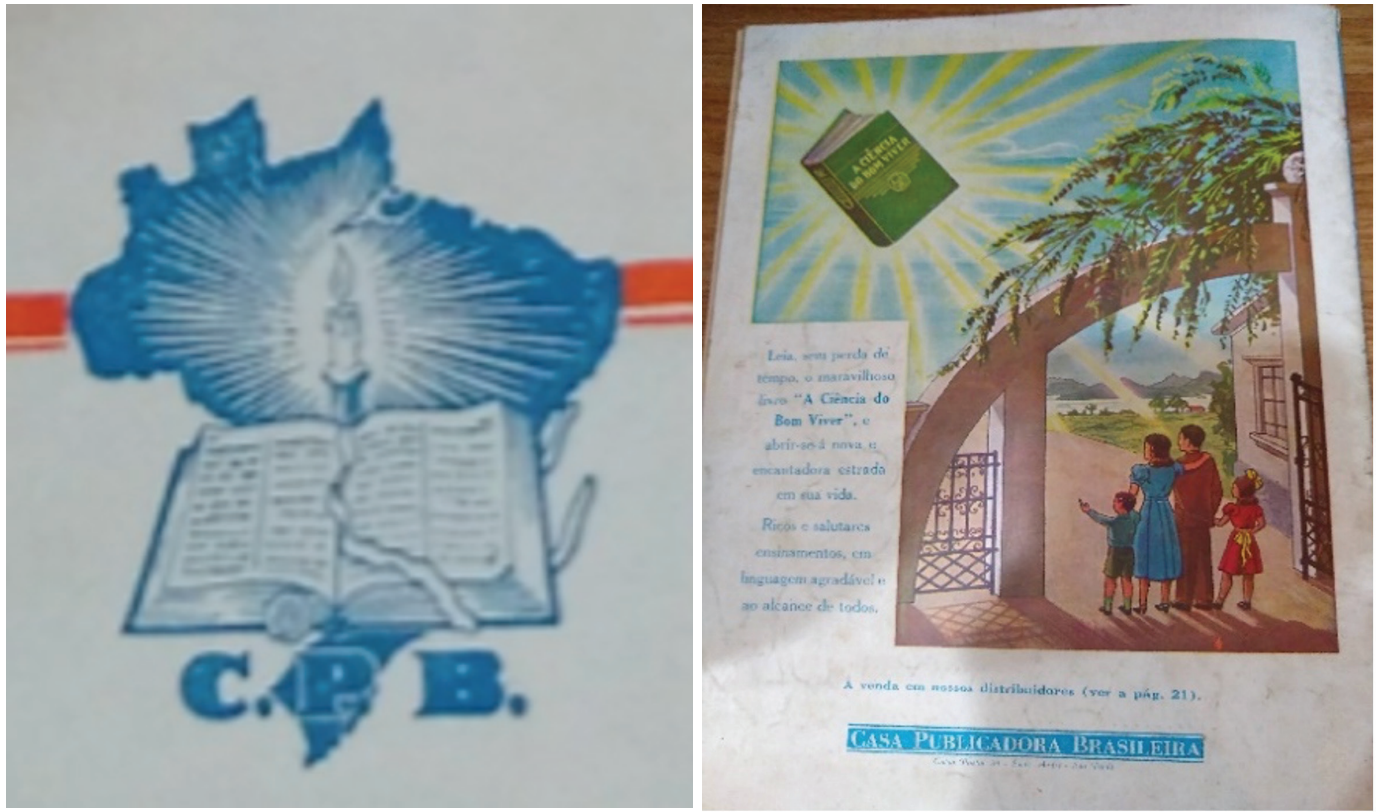

Fonte: Centro de Memória Ellen G. White - Unasp-EC

Destacamos essas ilustrações por mostrarem o imaginário adventista associado à leitura, que se repete em publicaçôes da primeira metade do século XX. Durante as primeiras décadas, as ilustraçôes eram mínimas, mas a partir do final dos anos 1930 houve incremento em imagens internas às publicaçóes e em capas coloridas de revistas como Vida e Saúde. Até os anos 1970, as publicaçôes adventistas seguiam padrôes de ilustração e de imagens semelhan- 
“AlisTANDO-SE NO INVENCÍVEL EXÉRCITO DA PÁGINA IMPRESSA" - CULTURA IMPRESSA ADVENTISTA NO BRASIL NO SÉCULO XX

Karina Kosicki Bellotti

tes aos das congêneres estadunidenses, refletindo o ideal de vida próxima à natureza como sinônimo de saúde, como no caso da revista Vida e Saúde - capas com fotos ou ilustraçóes de paisagens arborizadas, flores, frutas; ou então o ideal da família nuclear branca. Não havia um Departamento de Arte específico na CPB até os anos 1970, e não raro as ilustraçóes das revistas e livros não possuíam autoria conhecida.

$\mathrm{Na}$ revista Vida e Saúde, era comum haver ilustraçóes e fotos pertencentes à revista americana adventista Life and Health, que usava frequentemente bancos de imagens (BELLOTTI, 2020). O incremento nas imagens coincide com a popularização de publicaçóes seculares com fotojornalismo, como a revista O Cruzeiro (ALI, 2009). Da mesma forma, a revista infantil Nosso Amiguinho, iniciada em 1953, possuía elementos de composiçáo editorial semelhante à de outras publicaçóes infantis populares no Brasil, como a revista O Tico-Tico (ROSA, 2002), acrescido de conteúdo moral e cristão de autoria adventista (BELLOTTI, 2010). Essa é uma característica marcante das revistas adventistas para público não adventista - sua proximidade estética com formatos populares do momento em que são produzidas, com recursos visuais atrativos e sem proselitismo aparente. Os livros, por sua vez, são diferentes, com títulos que variam de saúde, casamento e nutrição aos livros com temáticas doutrinárias adventistas - estes eram feitos para serem distribuídos após uma familiaridade do/a leitor/a com a produçáo adventista.

No anúncio de dezembro de 1950 na revista Vida e Saúde, os livros são os melhores presentes para qualquer ocasiáo - Natal (seguindo a efeméride da publicaçáo), casamento ou aniversário - "tudo se acaba ou se perde - menos as ricas liçóes e os belos exemplos de moral dos bons livros. Seus ensinamentos permanecem no coração e produzem efeitos até para a vida eterna"6. A ideia de que os livros produzem efeitos duradouros confere um poder aos meios de comunicação sobre o intelecto e as emoçôes das pessoas, de tal forma que, ao se cercar de bons impressos, o indivíduo teria a possibilidade de progredir na vida; do contrário, sua vida seria uma lástima. Essa noção pressupóe que o sujeito seja uma tábula rasa, que necessitasse de uma tutela para desenvolver bons hábitos. Para Raymond Williams (1969), essa é uma concepçáo de cultura como algo a ser adquirido e cultivado a partir do consumo de produtos de "boa qualidade", em geral, quem determina o que é bom ou ruim é uma instância exterior ao sujeito, pertencente a uma elite intelectual. Um exemplo disso está na propaganda da revista Nosso Amiguinho, voltada para as crianças, editada pela Casa Publicadora Brasileira desde 1953:

Como o alimento fortifica o corpo - Assim a boa leitura robustece a mente

Histórias - passatempos [...] valorizam a leitura de NOSSO AMIGUINHO, caprichosamente preparada para a formação intelectual e moral da criança brasileira, ameaçada de intoxicação pela enorme e sempre crescente quantidade de literatura inferior e por isso mesmo deletéria,

${ }^{6}$ PROPAGANDA. Vida e Saúde, Santo André-SP, v. 12, n. 12, p. 24, Casa Publicadora Brasileira, dez. 1950. 
“AlisTANDO-SE NO INVENCÍVEL EXÉRCITO DA PÁGINA IMPRESSA" - CULTURA IMPRESSA ADVENTISTA NO BRASIL NO SÉCULO XX

Karina Kosicki Bellotti

que enche as bancas de jornais, e cujos efeitos vêm impressionando fortemente as famílias e as próprias autoridades. Assine NOSSO AMIGUINHO para suas crianças e lhes estará dando um alimento espiritual saudável ${ }^{7}$.

Nota-se a hipérbole dos efeitos deletérios da literatura de "qualidade inferior", sem que tenhamos ideia, no anúncio, de quais elas poderiam ser. Ao superdimensionar a má qualidade dos concorrentes, utilizando termos que remetem à intoxicação, o anunciante valoriza sua própria publicação, como "alimento espiritual saudável”. Se os produtos ruins interferem na família, efeito contrário se espera ao se consumir o alimento que "robustece a mente". Trata-se de uma analogia da "boa" literatura e da mídia como um nutriente, ressaltando seu caráter orgânico e natural, ocultando seu sentido de artefato, de construção humana. Essa ideia está presente na qualificação que grupos cristãos fazem de sua produção midiática, como alternativa à produção "mundana" ou secular, que estaria ameaçando a vida de seus filhos. Vemos isso na retórica da defesa dos "valores familiares" pela direita cristã norte-americana a partir dos anos 1970, e que ao longo do século XX aparece nos embates entre cristãos em torno do que é legítimo e "saudável" para crianças e jovens (KINTZ; LESAGE, 1998). Isso também tem ocorrido na história recente brasileira do ativismo de grupos evangélicos e católicos contra grandes empresas de comunicação secular, ou na sua vigilância em relação às expressóes artísticas de grupos LGBTQI+ e feministas, acusados de tentarem deturpar a formação de crianças e jovens.

Chartier (1994, p. 190) diferencia o tipo de leitura que o livro no suporte eletrônico tem em relação ao livro impresso - "livre composição de fragmentos indefinidamente manipuláveis [...]". Náo seria o apego ao livro uma forma de estabelecer o controle sobre o que é publicado - seu conteúdo, quem o produz, quem o divulga e quem o recebe? "A significação ou, antes, as significaçóes histórica e socialmente diferenciadas de um texto, seja qual for, não podem ser separadas das modalidades materiais por meio de que o texto é oferecido aos leitores" (CHARTIER, 1994, p. 194).

Por conseguinte podemos pensar o quanto o entretenimento ou a comunicação que náo é mediada pela "voz" religiosa são vistas com desconfiança - que o ato imaginativo presente tanto nesses veículos quanto no ato do seu consumo precisam ser tutelados, orientados "conduzido ou encurralado, o leitor encontra-se invariavelmente inscrito no texto, mas ele, por sua vez, inscreve-se de múltiplas formas em seus diferentes leitores" (CHARTIER, 1992, p. 215).

No artigo “Que qualidade de pessoas sois vós?”, o pastor Walter E. Murray (1894-1985), da área educacional da igreja, anunciou a campanha de leitura para os jovens da denominação para 1921, vinculando a qualidade da leitura com a formação do caráter:

${ }^{7}$ PROPAGANDA. Vida e Saúde, Santo André-SP, v. 18, n. 9, p. 24, Casa Publicadora Brasileira, set. 1956. 
“Alistando-SE No INVENCÍvel EXÉRCito DA PÁGINA IMPRESSA" - Cultura IMPRESSA ADVENTISTA No Brasil No SÉCULO XX

Karina Kosicki Bellotti

Que qualidade de homem ou mulher és tu? És forte e prudente, ou fraco e vacillante? Disse alguém: "Refira-me os livros que lês e dir-te-ei quem és". Conhece-se-nos pela companhia em que nos movemos". A leitura decide do nosso caracter. Se lemos livros úteis e ennobrecedores tornamo-nos fortes para encarar as exigências da vida. Se negligenciamos de ler bons livros, cessamos de desenvolver-nos intellectualmente, pára o nosso progresso espiritual e, quanto á moral, tornamo-nos pigmeus ${ }^{8}$.

Além disso, o livro parece ter vida própria, como o conselheiro da família, sem uma apresentação formal da sua autoria - os anúncios de $A$ ciência do bom viver não mencionam a autoria de Ellen G. White, importando, portanto, o conteúdo do livro e não a promoção individual de um autor. Na publicidade do livro O conselheiro médico do lar (SWARTOUT, 1942), o anúncio vaticina "Quem avisa, amigo é”:

em matéria de aquisição ou conservação da saúde, então, quem avisa é duplamente amigo. As ediçóes da Casa Publicadora Brasileira, sobre o assunto, são como verdadeiros amigos que avisam, aconselham e ensinam, trazendo uma esperança e cura a muito enfermo e, sobretudo, previnem muita enfermidade?

O livro era uma das publicações de saúde de tamanho extenso, com ilustraçóes do corpo e de procedimentos de primeiros socorros, com capa dura, feitos para serem passados de geração a geração. Trata-se de um contexto em que a maioria da população não contava com uma infraestrutura de atendimento gratuito de saúde, por isso, esse tipo de publicação visava oferecer um apoio nos momentos de apuro.

Destacamos na Figura 3 a representação da revista $O$ Atalaia, voltado para o público não adventista, que interpretava os eventos cotidianos à luz das profecias e da Bíblia. Na edição especial sobre colportagem, em agosto de 1940, no alto da ilustração, lê-se: “'O Atalaia’ está bem vestido e pronto para viajar em busca de almas". Abaixo, vemos a revista com feiçóes humanas, sorrindo, "caminhando" com pés e, em uma das mãos, segura uma bengala e, em outra, uma cartola. Ao lado, a inscrição: "os membros devem servir como pernas para 'O Atalaia'. É possível que nós andemos melhor que 'O Atalaia', mas 'O Atalaia' prega melhor que muitos evangelistas"10. A antropomorfização da mídia impressa chama atenção não somente pela ilustração utilizada, como pelo seu caráter quase autônomo - a revista precisa caminhar com a ajuda dos fiéis, mas tem a capacidade de pregar melhor que muitos ${ }^{11}$.

\footnotetext{
${ }^{8}$ MURRAY, Walter E. Que qualidade de pessoas sois vós?. Revista Mensal, São Bernardo do Campo-SP, v. 15, n. 11, p. 6, Casa Publicadora Brasileira, nov. 1920.

${ }_{9}^{9}$ PROPAGANDA. Vida e Saúde, Santo André-SP, v. 1, n. 5, p. 24, Casa Publicadora Brasileira, maio 1939.

${ }^{10}$ STRAHLE, John J. Com a rapidez do relâmpago. Revista Adventista, Santo André-SP, v. 35, n. 8, p. 2 , Casa Publicadora Brasileira, ago. 1940.

${ }^{11}$ Não há informação sobre a autoria da ilustração, como ocorre com a maioria das publicaçóes da CPB até os anos 1970, quando a editora estabeleceu um Departamento de Arte.
} 
Figura 3: Ilustração referente à revista O Atalaia (STRAHLE, 1940, p. 2)

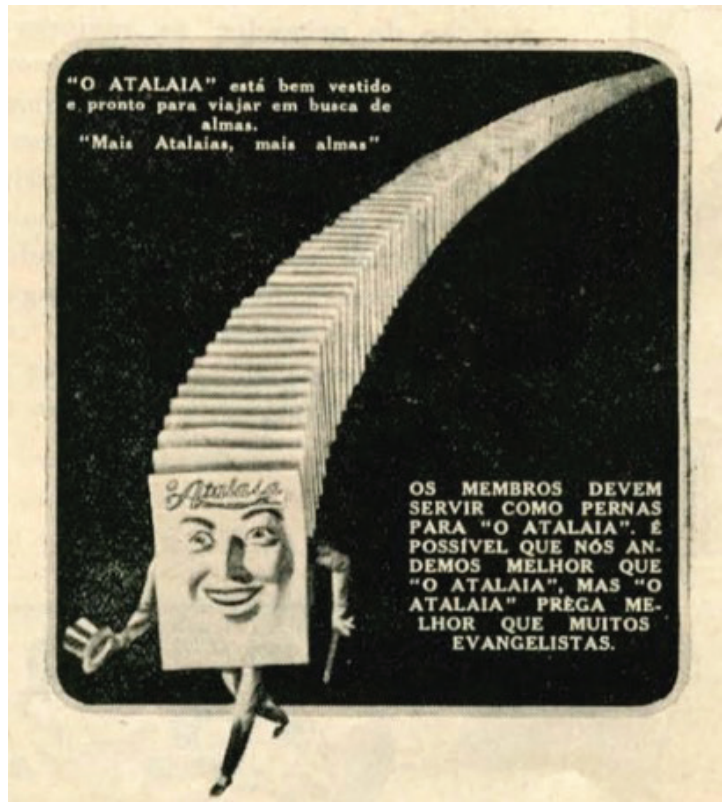

Fonte: https://acervo.cpb.com.br/ra

A forma como retratam os impressos náo difere muito entre os dois públicos - tanto o adventista quanto o não adventista - pois a mídia impressa aparece com poder transformador, de levar ao caminho correto e saudável, ainda mais se tiver um/a mediador/a - o/a colportor/a. O fato de os impressos adventistas serem concebidos numa visão missionária, à semelhança de outros impressos religiosos com essa natureza, apoia-se na ideia de que os leitores tenham um único tipo de leitura, isto é, que Deus aja sobre o leitor e a verdade lhe apareça. O colportor é o mediador que deve garantir a distribuição da maneira correta, fazendo o escrito "falar". Porém, segundo Certeau (1998, p. 259-273), a leitura é "uma operação de caça", uma ação imprevisível por parte do/a leitor/a. Assim, os adventistas oferecem dois dispositivos para direcionar a leitura: a composição dos seus livros como "leitura saudável" e esclarecedora e o/a colportor/a.

\section{Colportagem - "A bomba atômica espiritual"}

A colportagem, venda de porta em porta, é uma antiga prática de distribuição de impressos, popular na Europa desde o século XVIII, servindo para literatura religiosa e secular. No século XIX, a distribuição de impressos para fins evangelísticos ganhou impulso com entidades como a Sociedade Americana de Tratados e Sociedade Bíblica Americana, criadas na primeira metade do século XIX. Além de levar a mensagem religiosa, a colportagem es- 
“AlisTANDO-SE NO INVENCÍVEL EXÉRCITO DA PÁGINA IMPRESSA" - CULTURA IMPRESSA ADVENTISTA NO BRASIL NO SÉCULO XX

Karina Kosicki Bellotti

timularia a própria alfabetização e o consumo da "boa" leitura em meio à popularização de novelas e romances de baixo custo e temas nem sempre cristáos (MORGAN, 1999).

Quando a IASD surgiu, a colportagem era bem difundida nos Estados Unidos, e se tornou ferramenta indispensável na expansão da igreja. No Brasil, a distribuição de Bíblias foi uma das primeiras estratégias de difusão do protestantismo ainda na primeira metade do século XIX (MENDONÇA, 1995), e com a vinda de missionários estadunidenses a partir da segunda metade daquele século, a publicação e venda de periódicos e livros foi adotada pelas igrejas presbiteriana, metodista, congregacional e batista. No caso adventista, Ellen G. White aconselhou os membros da denominação por diversos escritos, reunidos em 1902 no livro Manual do colportor, e ampliado na obra póstuma O colportor-evangelista, de 1920. Desde os primórdios da Revista Adventista e de suas antecessoras havia testemunhos de colportores e exortaçôes para que outros membros da igreja assumissem essa tarefa.

Quem eram e são os colportores e as colportoras? Desde as primeiras décadas da igreja adventista no Brasil, as pessoas que desejavam distribuir impressos para instrução e evangelização deveriam fazer um curso de colportagem. Depois deveriam adquirir os impressos que venderiam, podendo ficar com uma porcentagem das vendas para se sustentar e poder comprar novos impressos. Até hoje é comum estudantes das instituiçóes adventistas de ensino superior colportarem para pagar seus estudos. A pessoa poderia se dedicar integralmente ou parcialmente ao serviço, sem distinção entre homens e mulheres. No início do século XX, o trabalho feminino ainda era restrito na esfera pública, mas os adventistas encorajavam o trabalho missionário, pois Deus garantiria o sucesso do trabalho das "irmãs" que desejassem trabalhar na colportagem, sendo uma atividade mais legítima do que trabalhar no "mundo":

Ao afirmar que nossas irmãs podem trabalhar "EFICAZMENTE" na venda de nossas revistas, o Senhor assegura o êxito das que aceitam este chamado divino. Em lugar de estar sem trabalho ou de trabalhar como servas ou em fábricas, escritórios ou escolas, em ambientes mundanos, nossas estimadas irmãs podem vender nossas revistas salvadoras e ser assim colportorasmissionárias ${ }^{12}$.

O trabalho feminino dedicado a Deus seria uma oportunidade permitida pelas instituiçôes protestantes para o protagonismo das mulheres. As representaçôes das colportoras assemelham-se às formas como missionárias protestantes figuram em outros discursos do campo protestante brasileiro e norte-americano. Trata-se de mulheres abnegadas, que não recuam diante das perseguiçóes dos inimigos do trabalho evangelístico (OLIVEIRA FILHO, 2018).

Contudo, nos periódicos adventistas a imagem prevalecente dessa atividade era masculina - o colportor, conforme exemplificamos com a imagem da capa da Revista Adventista

\footnotetext{
${ }^{12}$ RIFFEL, Juan; CHAIJ, Nicolás. Podem trabalhar eficazmente. Revista Adventista, Santo André-SP, ano 50, n. 12, p. 3-4, Casa Publicadora Brasileira, dez. 1955.
} 
em fevereiro de 1959 (Figura 4), em que o colportor apresenta a um casal um catálogo de livro, enquanto Jesus Cristo aparece atrás do vendedor, iluminando todo o recinto. Seguindo uma estética predominante nas revistas adventistas até os anos 1980, os representados são brancos, aparentemente de classe média, a notar pelo mobiliário e pelas roupas. Porém, na Revista Adventista constatamos que dentre as fotos dos e das colportores/as havia muitos negros e pardos, sendo uma minoria de mulheres, como vemos na foto da Figura 5, de outubro de 1940, em que havia nove homens e três mulheres na turma do curso de colportagem de Manaus. As fotos nas ediçôes da Revista Adventista nos mostram um descompasso entre a autoimagem que a igreja fazia de si e de seus sujeitos nas capas de suas publicaçôes e a realidade encontrada entre seus fiéis e lideranças.

Figura 4: Capa da Revista Adventista de fevereiro de 1959
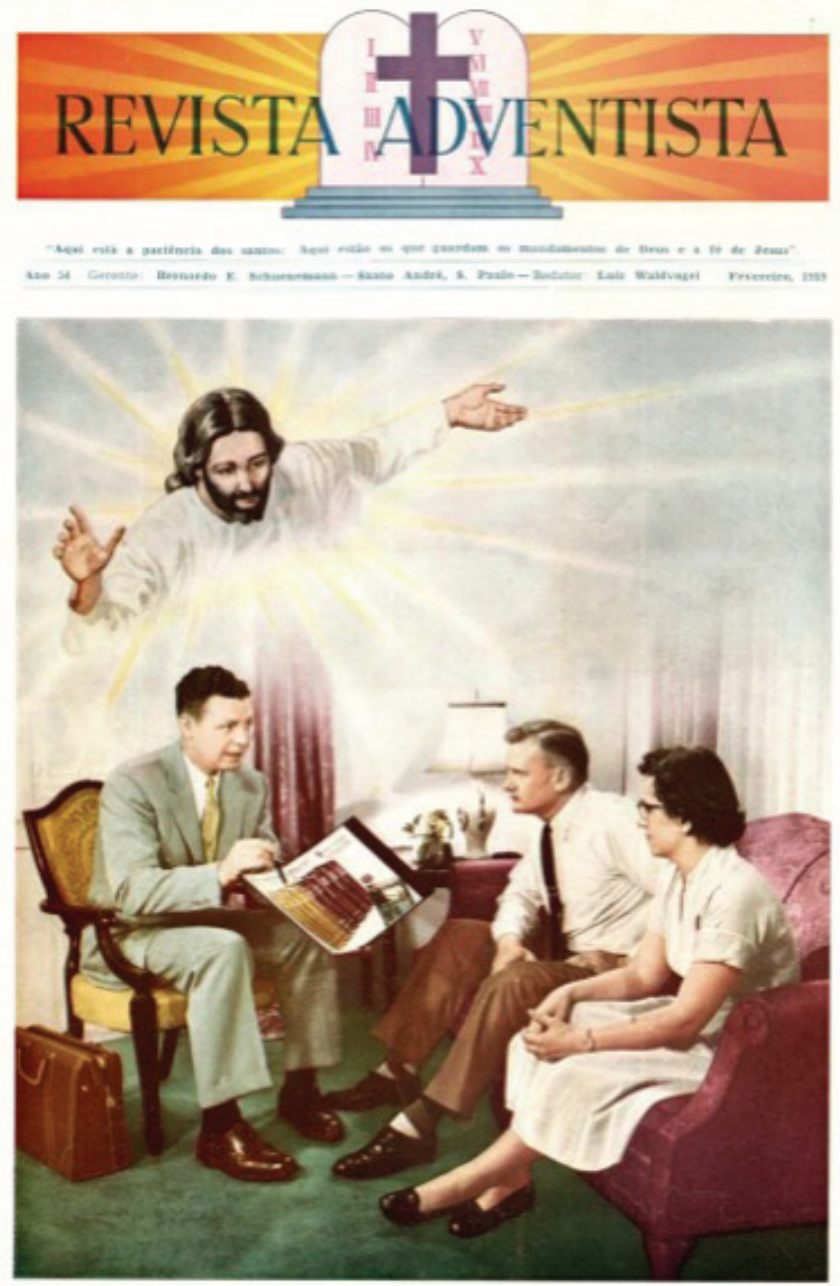

Fonte: https://acervo.cpb.com.br/ra. 


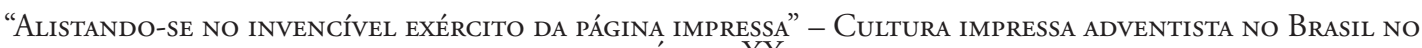
SÉCULO XX

Karina Kosicki Bellotti

Figura 5: Foto de colportores de Manaus em 1940 (PARENTE, 1940, p. 10)

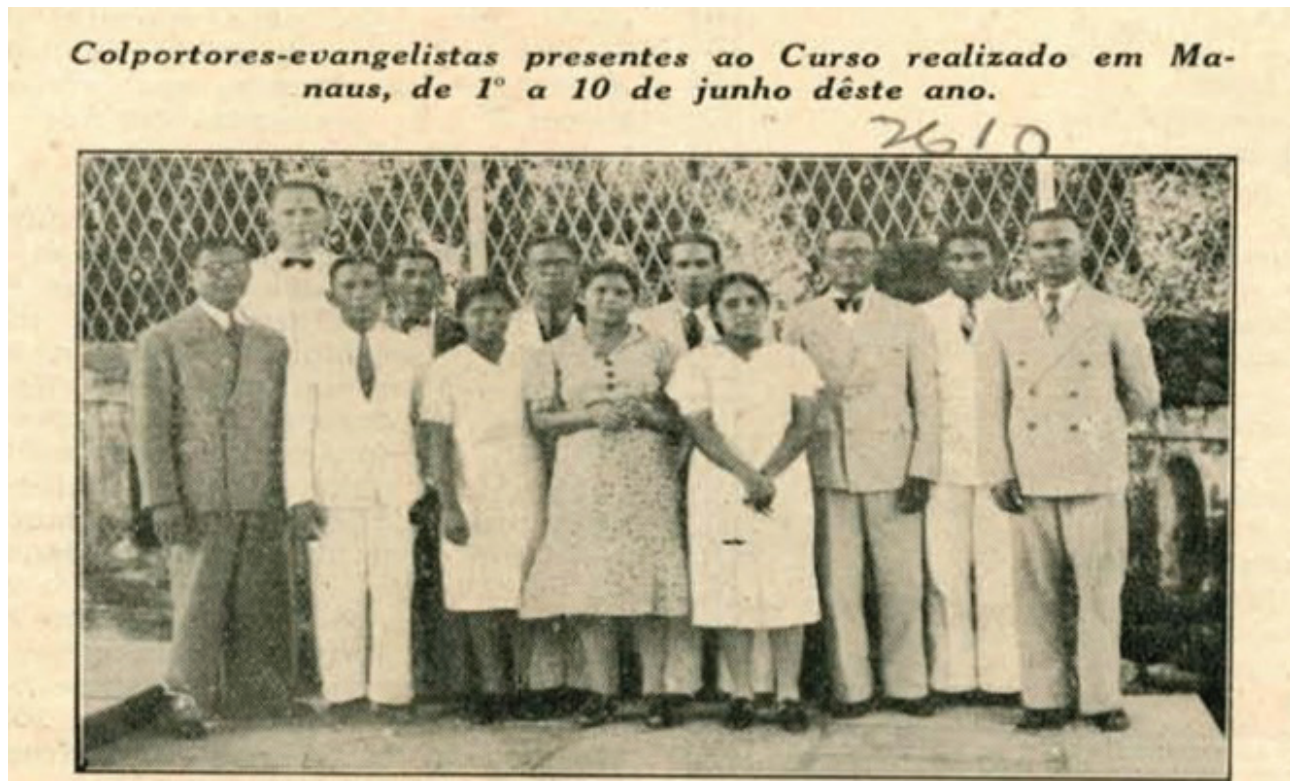

Fonte: https://acervo.cpb.com.br/ra

Não obstante, a Revista Adventista divulgou a atividade de colportoras. Desde os anos 1920 a Revista Mensal solicitava aos seus colaboradores que enviassem fotos de seu trabalho no campo missionário, junto aos relatos feitos em primeira pessoa ou por terceiros. As "valorosas colportoras" aparecem em retratos mais frequentemente nas décadas iniciais da revista - como no caso das irmás Macedo ${ }^{13}$, montadas em seus cavalos, tal como alguns colportores que posavam com seu cavalo ou burro usado na colportagem. Uma pose mais comum é a do/a colportor/a ao lado de uma pilha de livros embrulhados, como é o caso de Aurelina P. Rodrigues, que assina o texto "Vitória"14 , sobre seu trabalho de colportagem, em que enfrentou com tranquilidade e sabedoria a oposição de um padre. Em boa parte das fotos, tanto homens quanto mulheres estão de roupa social, bem alinhados/as, segurando um livro na mão e/ou posando com seu cavalo, ou carro usado na colportagem. Não raro os textos destacam o quanto as mulheres arrecadaram dinheiro para construir templos, escolas, e demais benfeitorias para a comunidade. Uma pesquisa mais detida sobre as narrativas de colportagem de homens e mulheres ainda está para ser feita, e material para consulta não falta.

Ao realizarmos busca pelos termos colportor(es), colportora(s) e colportagem em 93 anos da Revista Adventista, de 1906 a 1999, observamos (Gráfico 1) que há uma contrastante diferença entre as numerosas referências aos colportores e as parcas referências às colportoras, em

\footnotetext{
${ }^{13}$ ANNIEHS, Arnaldo. A colportagem ganhando um colportor. Revista Adventista, Santo André-SP, ano 44, n. 12, p. 12, Casa Publicadora Brasileira, dez. 1949.

${ }^{14}$ RODRIGUES, Aurelina P. Vitória. Revista Adventista, Santo André, v. 34, n. 11, p. 13, Casa Publicadora Brasileira, nov. 1939.
} 
“Alistando-SE No INVENCÍvel EXÉRCito DA PÁGINA IMPRESSA" - Cultura IMPRESSA ADVENTISTA No Brasil No SÉCULO XX

Karina Kosicki Bellotti

intervalos de dez em dez anos. Na revista, as palavras indexadas como "colportor" também incluem o plural "colportores", e o feminino "colportora", com seu respectivo plural.

Gráfico 1: Frequência de mençôes a colportor(es), colportora(s) e colportagem na Revista Adventista de 1906 a 1999

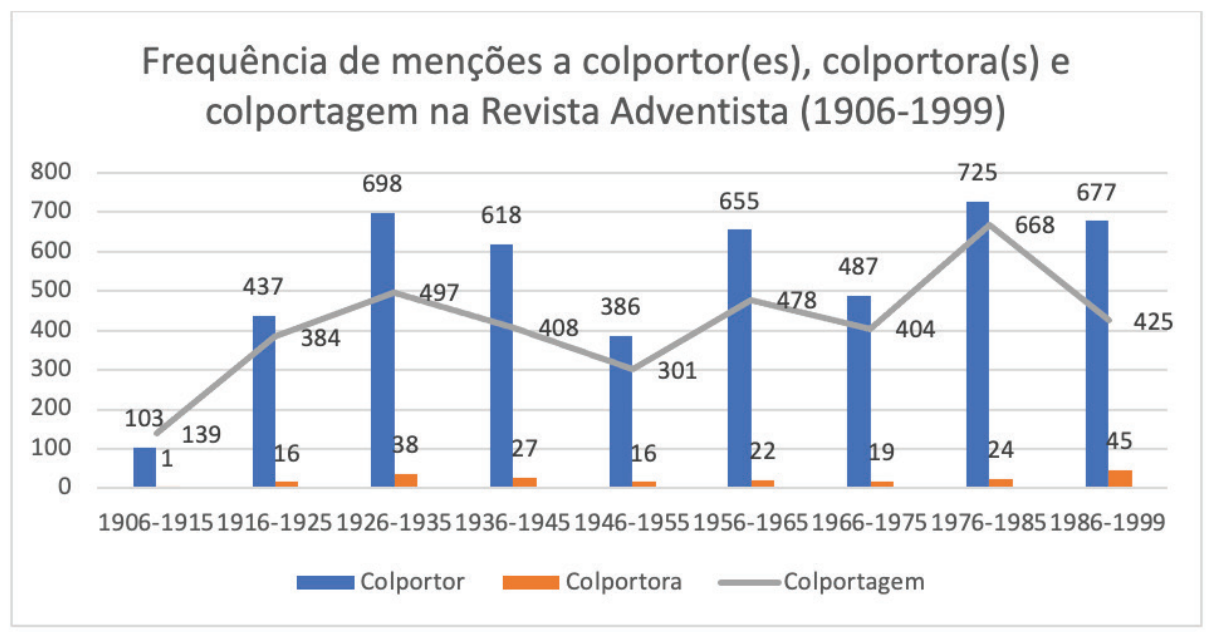

Fonte: A pesquisadora

No Gráfico 1, vemos que o agente predominante da colportagem é masculino. Ao separar a busca pelo termo feminino, vemos que as colportoras foram muito menos mencionadas pela revista, permanecendo em um número de citaçóes que varia de 16 a 57, numa média de cerca de 20 a 30 citaçôes por década. Isso significa que durante meses as colportoras não foram citadas, enquanto seus colegas colportores foram citados em abundância em todas as décadas, mesmo nas últimas quatro décadas, quando as referências à colportagem apresentam tendência de queda constante ${ }^{15}$.

Essas mençóes referem-se aos relatos das atividades colportoras, mas náo espelham a totalidade da prática colportora no Brasil, perdurando por décadas, com o objetivo de engajar os membros da denominaçáo para a atividade. Na revista, foi divulgado um perfil ideal de colportor entremeado aos relatos das experiências de trabalho. Além disso, a igreja estabelecia as principais condutas que os colportores deveriam ter em relação ao seu público-alvo, em relação à Casa Publicadora e à IASD, criticando as falhas e desvios de conduta, como a falta de disciplina, a desistência após curto período de trabalho e a baixa venda.

\footnotetext{
${ }^{15}$ Ainda que a palavra "colportor" seja um substantivo e um adjetivo, vemos que sua grande presença nesse levantamento da revista indica a predominância masculina conferida à atividade. Já o adjetivo "colportora" também está incluído nesse levantamento, referindo-se principalmente às lanchas colportoras que atuavam nas regiôes amazônicas. Isso significa que a menção ao trabalho das mulheres colportoras pode ser ainda menor do que o Gráfico 1 mostra.
} 
“AlistANDO-SE NO INVENCÍvel EXÉRCito DA PÁGINA IMPRESSA" - Cultura IMPRESSA ADVENTISTA No Brasil No SÉCULO XX

Karina Kosicki Bellotti

O que nos intriga é que a referência à colportagem e a colportores/as na Revista Adventista tenha diminuído justamente a partir do período em que a CPB inaugurou sua nova sede em Tatuí-SP, com parque gráfico ampliado e crescente capacidade de impressão. Algumas especulaçóes precisam ser comprovadas por pesquisas futuras: seria essa menção reduzida na Revista Adventista um sinal de que a prática da colportagem estaria consolidada e difundida entre a comunidade adventista? Ou seria essa queda um indício de que a igreja estaria interessada em outros assuntos, ficando a colportagem em segundo plano, ainda mais nos períodos em que a revista aumentou seu número de páginas ${ }^{16}$ ?

De qualquer forma, qualidades destacadas tanto nos testemunhos de colportores brasileiros quanto na narrativa de colportagem feita fora do Brasil foram: abnegação, serviço cristão, sacrifício ao enfrentar condiçóes difíceis de trabalho, coragem, firmeza de caráter, perseverança. $\mathrm{O}$ intuito era mostrar que as publicaçôes adventistas eram distribuídas nos lugares mais distantes, desafiando os leitores brasileiros a seguir o exemplo dos irmãos de outros países.

Em dezembro de 1908, Augusto Pages ${ }^{17}$ afirmou que a colportagem era "um dos meios mais importantes para anunciar a mensagem dos grandes acontecimentos futuros com sucesso em todos os países". Por isso, seria o meio mais combatido por Satanás, fazendo do colportor uma presa fácil, ainda mais se fosse inexperiente. Havia colportores que queriam se tornar pregadores depois de pouco tempo de trabalho no campo, pois acreditavam ser a colportagem uma ocupação menor. Pages deu o exemplo do "irmão Anderson", que era incansável no seu ofício, enfrentando todo tipo de intempéries:

[...] si o nosso jornal tem na Islândia 4.000 assignantes (não ha lá outro jornal que tenha tantos assignantes), é isto devido ao trabalho incançavel e desinteressado do irmão Anderson. No verão elle está desde pela manhã até á noite a Cavallo. Muitas vezes, ao transpor os rios, elle é obrigado a levar os livros e tratados sobre a cabeça e a atravessar o rio conduzindo o cavallo pelas rédeas. No inverno elle vae a pé, sem que o sol lhe sorrie uma só vez [... $]^{18}$.

As dificuldades são descritas em detalhes - percursos geográficos tortuosos, intempéries, climas severos (alagamentos, neve, calor), parcos recursos para vencer as distâncias, além da hostilidade e violência vindas de opositores do trabalho adventista - padres, pastores de outras igrejas protestantes, beatas, anônimos, líderes políticos. Não raro, os problemas

\footnotetext{
${ }^{16}$ A Revista Trimensal (1906-1908) possuía 12 páginas em preto e branco; a Revista Mensal (1908-1931) tinha oito páginas de 1908 a 1918; e de 1918 a 1931, 16 páginas. A partir de 1931, quando mudou seu título para Revista Adventista, passou a ter 32 páginas, a partir de 1977, possuía 48 páginas. A revista possuiu cerca de 40 páginas entre os anos 1980 até 2015 , ano em passou a ter as atuais 52 páginas.

${ }^{17}$ PAGES, Augusto. Experiência na colportagem. Revista Mensal, São Bernardo-SP, v. 2, n. 12, p. 5-6, Casa Publicadora Brasileira, dez. 1908.

${ }^{18}$ Idem.
} 
“AlistANDO-SE NO INVENCÍVEL EXÉRCITO DA PÁGINA IMPRESSA” - CUlTURA IMPRESSA ADVENTISTA No BRASIL NO SÉCULO XX

Karina Kosicki Bellotti

eram atribuídos à ação de Satanás, que desejaria frear o conhecimento da "verdade" cristã e investiria com força sobre os cristáos. Como parte de uma narrativa exemplar, os colportores descrevem suas vitórias alcançadas com inteligência, polidez e resiliência e a ajuda de Deus, convencendo os coraçôes mais empertigados a ouvi-los e até comprar literatura e revista.

As dificuldades relatadas sempre eram recompensadas: pela venda da literatura, convertendo-se em renda para o colportor para sua sobrevivência; pela divulgação da mensagem adventista; e pela proteçáo divina. A analogia da colportagem como um esforço de guerra contra Satanás transforma seus agentes em soldados, obedecendo a um comandante maior. O sargento do Corpo de Bombeiros, Plácido da Rocha Pita, que havia saído da corporação após se converter ao adventismo, tornou-se colportor em tempo integral e afirmou em depoimento à revista: "Alistei-me agora, voluntariamente, no invencível exército da página impressa, cujo General está sentado à destra do Senhor Deus todo-poderoso"11.

Além desse sentido de missão, que confere um propósito forte aos colportores, vemos relatos que garantem a ação divina nos momentos mais dramáticos, como no caso do relato feito por J. Berger Johnson, editor da Revista Adventista em novembro de 1930. Ao discorrer sobre a colportagem na Europa, ele contou o caso de um colportor náo identificado na regiâo báltica que fez encomendas em todas as residências de uma região, mas sofreu represália do padre, que ameaçou demover todos os moradores de suas compras:

Nossos colportores estão tendo muitas experiências interessantes. Alguns delles, porém, encontram muita opposiçáo. [...] O colportor ficou um tanto desapontado [com a reaçáo do padre], mas retirou-se para seu quarto e buscou fervorosamente ao Senhor. Antes que o padre pudesse começar sua planejada missão, adoeceu, sendo obrigado a ficar de cama. Assim ficou muitos dias. Com effeito, não pôde sahir de casa antes que o colportor houvesse entregue todos os seus livros. Assim frustrou o Senhor os esforços do inimigo para estorvar Sua obra. Como é verdade que não podemos fazer nada contra a verdade, mas só pela verdade! ${ }^{20}$.

No texto "Tem valor a colportagem?" ${ }^{21}$, Adolpho Astheziano defendeu que o colportor é o especialista em identificar o que falta à pessoa visitada, indicando-lhe a melhor leitura. Assim, não bastava saber o que distribuir, mas como distribuir. Nos conselhos para a distribuição de impressos prevalece a noção de que o distribuidor ou colportor devem fazer sua parte, e que Deus saberia como melhor encaminhar a sua palavra e fixar suas sementes nos solos apropriados:

\footnotetext{
${ }^{19}$ PITA, Plácido da Rocha. Mais uma vitória para o Príncipe Emanuel. Revista Adventista, Santo André-SP, v. 35, n. 8, p. 12-13, Casa Publicadora Brasileira, ago. 1940.

${ }^{20}$ JOHNSON, J. Berger. Echos da Conferência Mundial dos A.S.D. - a divisão septentrional da Europa. Revista Adventista, Santo André-SP, v. 35, n. 8, p. 2-3, Casa Publicadora Brasileira, nov. 1930.

${ }^{21}$ ASTHEZIANO, Adolpho. Tem valor a colportagem?. Revista Mensal, Sáo Bernardo-SP, v. 7, n. 10 e 11, p. 13, Casa Publicadora Brasileira, out.-nov. 1912.
} 
“AlistANDO-SE NO INVENCÍvel EXÉRCito DA PÁGINA IMPRESSA" - Cultura IMPRESSA ADVENTISTA No Brasil No SÉCULO XX

Karina Kosicki Bellotti

São eles somente os que podem conhecer o povo e a necessidade que tem de um Salvador. Trabalhando fielmente todos os dias, podemos dar bom testemunho de fidelidade, podemos dar excelentes exemplos aos homens e mostrar-lhes o caminho que conduz à vida eterna [...] O colportor, como diz o missionário Archibaldo, "possui uma chave que abre as portas, para outros fechadas" 22 .

Dentre os impressos para colportagem, destacam-se os escritos sobre saúde, voltados primeiramente para o público náo adventista. $\mathrm{O}$ primeiro livro de saúde traduzido para o português comissionado pelos adventistas foi $O$ lar e a saúde da família, lançado em 1913 pela CPB. Em fevereiro de 1912, Augusto Pages escreveu o texto "Fundo para a publicação e um livro sobre saúde em portuguez" ${ }^{23}$. Nele, trouxe a carta de Edwin R. Palmer, da Conferência Geral (órgão máximo da igreja), sobre qual era o melhor livro para distribuir em países católicos. Livros religiosos [leia-se: com doutrinas adventistas] como A grande controvérsia fecham as portas, por exigirem um grau de compreensão das doutrinas da igreja que estariam distantes da realidade dos católicos. Segundo o “irmão Green”, do México, quando os católicos veem primeiro um livro sobre saúde, o livro religioso tende a ser aceito depois, ideia reafirmada pelo “irmão Martin” (não há indicação do seu nome completo):

Deus serviu-nos dos livros de saúde para abrir o caminho para a venda dos livros religiosos. O espírito da profecia nos instruiu de que os livros e a obra de saúde nos foram dadas para esse fim. Diz-nos que o Salvador usou três quartos do seu tempo para fazer obra de missão, mostrando-se o grande Médico, e desta forma preparava os coraçóes dos homens para aceitar a mensagem de salvação, que Ele nos trouxe $[. . .]^{24}$.

Essa justificava direcionada aos leitores da Revista Adventista para que contribuíssem com o fundo para publicação está calcada em duas ideias centrais: primeiro, o melhor cartão de visitas para os livros religiosos e, posteriormente, para uma conversão adventista eram os livros de saúde; segundo, apostar na mensagem e na missão da saúde seria seguir o exemplo de Jesus, que curou os doentes como forma de "preparar os coraçôes" para a mensagem de salvação. O que significa que negar-se a contribuir para essa missão seria contrariar o exemplo do próprio salvador. Nessa edição de fevereiro de 1912, os editores foram duros com seus leitores pela baixa arrecadação alcançada até aquele momento.

As estratégias de distribuição de Vida e Saúde foram explicadas em ediçóes da Revista Adventista em 1939. Em agosto de 1939, o colportor Davi Tschurtschenthaler narra seu

\footnotetext{
${ }^{22}$ Idem.

${ }^{23}$ PAGES, Augusto. Fundo para a publicação e um livro sobre saúde em portuguez. Revista Mensal, São Bernardo-SP, v. 7, n. 2, p. 4-6, Casa Publicadora Brasileira, fev. 1912.

${ }^{24}$ PAGES, Augusto. A organização da Conferência União Brazileira. Revista Mensal, São Bernardo-SP, v. 6, n. 1, p. 1-4, Casa Publicadora Brasileira, jan. 1911.
} 
“AlistANDO-SE NO INVENCÍvel EXÉRCito DA PÁGINA IMPRESSA" - Cultura IMPRESSA ADVENTISTA No Brasil No SÉCULO XX

Karina Kosicki Bellotti

trabalho em Santa Catarina e no Paraná, apresentando-se para figuras de autoridade, funcionários públicos, médicos e direçáo do grupo escolar na cidade de trabalho. A diretora do grupo escolar de União da Vitória (PR), cuja mãe era adventista, acabou por fazer todas as professoras assinarem Vida e Saúde, além de fazer uma assinatura para a biblioteca da escola:

[...] Em primeiro lugar visitámos os prefeitos de ambas as cidades, os quais de bom grado encomendaram o Vencedor em combinação com Vida e Saúde. Em seguida visitámos outras personalidades de influência e empregados públicos que, com poucas exceçôes, assinaram a revista, dando-lhe todo o seu apoio e desejando bom sucesso, notadamente os médicos. O que de mais importante nos aconteceu foi quando visitámos o grupo escolar de União da Vitória. O diretor não estava presente, mas ficara em seu lugar uma irmã sua, distinta professora que já conhecia a revista, bem como a verdade, pois sua mãe é adventista. [...] Assim, em poucos dias tomámos mais de oitenta encomendas para o Vencedor em Todas as Batalhas em combinaçáo com Vida e Saúde ${ }^{25}$.

Em novembro de 1946, o colportor Lourival Ferreira narra a venda de 3 mil exemplares do livro $O$ decálogo da saúde, lançado em 1945 pela CPB. O dono de uma grande empresa (não cita nem o nome da companhia nem da cidade) teria encomendado 3 mil exemplares do livro para dar de presente de Natal para seus funcionários no final de ano. O comprador conheceu o livro por meio de propaganda na revista Vida e Saúde ${ }^{26}$. Relatar grandes montantes de venda representava uma grande vitória, acompanhada de súplicas do colportor pelas bençãos de Deus para que as vendas continuassem e mais almas fossem agraciadas pela sua palavra.

Em agosto de 1948, foi publicado o texto "A bomba atômica espiritual", de D. Pereira da Silva ${ }^{27}$ : "Não é a colportagem a bomba atômica espiritual?" (grifo original). Para o autor, a colportagem é a forma de divulgar a mensagem da "gloriosa volta de Cristo" para todas as pessoas, em qualquer lugar, de qualquer extrato social e religioso. $\mathrm{O}$ autor narrou suas andanças pelo Estado do Espírito Santo, ressaltando a boa forma dos adventistas e de seus livros: não fossem os impressos, muitas pessoas jamais seriam alcançadas.

Este trabalho da página impressa é realmente um trabalho atómico, porque vemos o seu efeito por cidades e roças de todas as partes. Encontramos livros e mais livros nos lares de gente de todas as crenças, os quais realmente têm quebrado o preconceito de muitos. São livros e revistas

\footnotetext{
${ }^{25}$ TSCHURTSCHENTHALER, Davi. O vencedor. Revista Adventista, Santo André-SP, v. 33, n. 8, p. 20, Casa Publicadora Brasileira, ago. 1939.

${ }^{26}$ FERREIRA, Lourival. Três mil livros. Revista Adventista, Santo André-SP, v. 41, n. 11, p. 21, Casa Publicadora Brasileira, nov. 1946.

${ }^{27}$ SILVA, D. Pereira da. A bomba atômica espiritual. Revista Adventista, Santo André, v. 43, n. 11, p. 8, Casa Publicadora Brasileira, ago. 1948.
} 


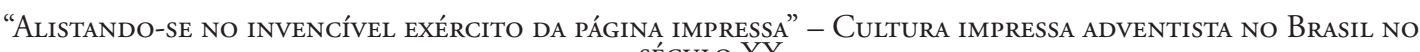
SÉCULO XX

Karina Kosicki Bellotti

vendidos, com ordem divina, pelos humildes colportores e colportoras, livros que se vêem nas grandes bibliotecas dos médicos e advogados, e no velho caixote da mais pobre criatura. Isto tem feito o povo pensar e examinar as Santas Escrituras ${ }^{28}$.

É interessante notar como o autor ressignifica a ideia de bomba atômica para um destino surpreendentemente positivo. À semelhança da bomba atômica, que se espalhou rapidamente de forma uniforme por todos os lugares onde foi detonada (as cidades de Hiroshima e Nagasaki), os impressos adventistas estariam por todos os lugares. Porém, a analogia de Silva ignora o efeito devastador e mortífero das bombas, e prefere enfocar o seu aspecto onipresente e irresistível, uma forma de valorizar o efeito do trabalho de distribuição, conferindo caráter triunfante independentemente das circunstâncias.

\section{"Fé na literatura" - consideraçôes finais}

Até hoje, a Igreja Adventista aposta na colportagem de revistas como Vida e Saúde e Nosso Amiguinho, além de livros de saúde, de receitas e religiosos. A experiência da colportagem e a própria significação da mídia impressa continuam ligadas a uma visão providencial, pois Deus guiaria os vendedores para as "pessoas certas". Mas isso não eximia a igreja de planejar diante das mudanças no mercado editorial e na mídia.

Almir Marroni (2016, p. 38-39), diretor do Departamento de Publicações da sede mundial adventista em Silver Spring, nos Estados Unidos, defendeu dez razôes para se ter "fé na literatura", pois é tarefa dos adventistas distribuir a literatura missionária, seguindo orientação do espírito de profecia, manifestado nos escritos de Ellen G. White. Mesmo com os meios modernos e eletrônicos, as páginas do livro continuam relevantes e são complementadas pelos outros meios.

A lógica de distribuição da colportagem investe os e as vendedores/as com o senso missionário, conferindo uma importância para a mídia impressa que dificilmente imaginaríamos encontrar em plena época da internet. Tanto no passado quanto no presente, a prática da colportagem tem sido uma aliada importante na inserção da IASD na sociedade brasileira, oferecendo uma possibilidade de pessoas leigas se sentirem parte da iniciativa missionária, fazendo amizades, indicando leituras, "fidelizando" seus clientes ao longo dos anos, fossem eles adventistas ou não. Nesse sentido, a permanência dos impressos marca uma constância na forma de atuar da IASD em toda sua história. Nos estudos de mídia e religiáo, a cultura impressa tem um lugar de destaque até hoje, seja pelo mercado editorial religioso com sua diversidade de títulos e denominaçôes, seja pela presença de igrejas e editoras que se mantêm ao longo de décadas. 
“AlisTANDO-SE NO INVENCÍVEL EXÉRCITO DA PÁGINA IMPRESSA" - CULTURA IMPRESSA ADVENTISTA NO BRASIL NO SÉCULO XX

Karina Kosicki Bellotti

Este artigo pretendeu traçar um panorama da permanência da mídia impressa na IASD, lançando questóes que venham a inspirar futuros trabalhos tanto sobre cultura impressa como pela colportagem, tanto na denominação adventista quanto em outras igrejas que conferem importância aos impressos. A vantagem de trabalho com a IASD deve-se ao facilitado acesso ao farto material para consulta online, que permite explorar mais de cem anos de publicaçóes.

Um aspecto que merece aprofundamento é a questão de gênero na colportagem, para observar se as narrativas ao longo dos anos na Revista Adventista ressaltam elementos diferentes de mediação entre colportores e colportoras, tendo em vista sua desproporção de mençôes na revista. Além disso, a questão étnico-racial merece atenção, tendo em vista a relação entre a predominância por décadas das representaçôes caucasianas dos colportores e sua diversidade racial e regional presentes nas próprias páginas do periódico. Somente nos últimos anos é que vemos aumentar a representatividade afro-brasileira nos periódicos adventistas, acompanhando tendência presente na mídia secular.

Destacaram-se ao longo desta pesquisa as visôes sobre leitura e a influência dos impressos cultivadas pelos adventistas, que estavam e ainda estão intimamente ligadas às suas estratégias de expansão, pois seguem a direção adotada desde os primórdios da igreja. Elas também estiveram ligadas a um imaginário de valorizaçáo da cultura como agente transformador e civilizador desde o final do século XIX, e que até hoje perdura, influenciando na maneira como adventistas - e outras denominações cristâs - concebem a cultura, educação, mídia e entretenimento.

Isto é, elas são vistas como detentoras de poder de influência, em especial entre os jovens, seja para levar a benção, seja para levar a desgraça. Os adventistas lançam mão desta noção de cultura para legitimar sua própria cultura impressa, como parte da "boa" literatura, ao mesmo tempo em que concebe sua distribuição como um mandato divino. Ainda que a colportagem não possua na Revista Adventista o mesmo espaço que possuía nas décadas iniciais, observamos que a cultura impressa ainda tem elevada importância para este grupo, acompanhando a valorizaçáo do racionalismo, da ciência e do letramento para sua formaçáo e para a atuação na sociedade, com sua rede de colégios e de hospitais.

Em meio a um mercado editorial religioso apoiado em vendas de autoajuda, a mídia impressa adventista mantém-se atuante, seguindo a noção de que o consumo de mídia "saudável" seria o antídoto das más influências mundanas. Continuam a se ver como a igreja detentora da verdade, e, com "fé na literatura" e em outros meios de comunicação, esperam convencer a todos disto. Este estudo de caso visa oferecer, portanto, uma reflexáo sobre as relaçôes entre grupos religiosos e suas relaçôes com a mídia produzidas por eles, e com a mídia externa à comunidade. Almejamos estimular outros trabalhos atentos para a forma como atores religiosos lidam com mídia e cultura no passado e, sobretudo, no presente. 


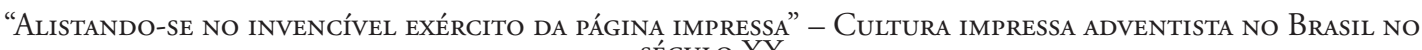
SÉCULO XX

Karina Kosicki Bellotti

\section{Fontes primárias}

ANNIEHS, Arnaldo. A colportagem ganhando um colportor. Revista Adventista, Santo André-SP, ano 44, n. 12, p. 12, Casa Publicadora Brasileira, dez. 1949.

ASTHEZIANO, Adolpho. Tem valor a colportagem?. Revista Mensal, São Bernardo-SP, v. 7, n. 10 e 11, p. 13, Casa Publicadora Brasileira, out.-nov. 1912.

CAPA. Revista Adventista. Santo André-SP, ano 54, n. 2, Casa Publicadora Brasileira, fev. 1959.

FERREIRA, Lourival. Três mil livros. Revista Adventista, Santo André-SP, v. 41, n. 11, p. 21, Casa Publicadora Brasileira, nov. 1946.

JOHNSON, J. Berger. Echos da Conferência Mundial dos A.S.D. - a divisão septentrional da Europa. Revista Adventista, Santo André-SP, v. 35, n. 8, p. 2-3, Casa Publicadora Brasileira, nov. 1930.

MURRAY, Walter E. Que qualidade de pessoas sois vós?. Revista Mensal, São Bernardo do Campo-SP, v. 15, n. 11, p. 6, Casa Publicadora Brasileira, nov. 1920.

PAGES, Augusto. A organização da Conferência União Brazileira. Revista Mensal, São Bernardo-SP, v. 6, n. 1, p. 1-4, Casa Publicadora Brasileira, jan. 1911.

PAGES, Augusto. Experiência na colportagem. Revista Mensal, São Bernardo-SP, v. 2, n. 12, p. 5-6, Casa Publicadora Brasileira, dez. 1908.

PAGES, Augusto. Fundo para a publicação e um livro sobre saúde em portuguez. Revista Mensal, São Bernardo-SP, v. 7, n.2, p. 4-6, Casa Publicadora Brasileira, fev. 1912.

PARENTE, Alcides. Curso de colportagem em Manaus. Revista Adventista, Santo André-SP, ano 54, n. 10, p.10-11, Casa Publicadora Brasileira, out.1940.

PITA, Plácido da Rocha. Mais uma vitória para o Príncipe Emanuel. Revista Adventista, Santo André-SP, v. 35, n. 8, p. 12-13, Casa Publicadora Brasileira, ago. 1940.

PROPAGANDA. Vida e Saúde, Santo André-SP, v. 4, n. 7, p. 24, Casa Publicadora Brasileira, jul. 1942.

PROPAGANDA. Vida e Saúde, Santo André-SP, v. 17, n. 8, p. 24, Casa Publicadora Brasileira, ago. 1955.

PROPAGANDA. Vida e Saúde, Santo André-SP, v. 12, n. 12, p. 24, Casa Publicadora Brasileira, dez. 1950.

PROPAGANDA. Vida e Saúde, Santo André-SP, v. 18, n. 9, p. 24, Casa Publicadora Brasileira, set. 1956.

PROPAGANDA. Vida e Saúde, Santo André-SP, v. 1, n. 5, p. 24, Casa Publicadora Brasileira, maio 1939. 
“Alistando-SE No INVENCÍvel EXÉRCito DA PÁGINA IMPRESSA" - Cultura IMPRESSA ADVENTISTA No Brasil No SÉCULO XX

Karina Kosicki Bellotti

QUEM SÃO OS ADVENTISTAS. Portal Adventistas. Disponível em: https://www. adventistas.org/pt/institucional/os-adventistas/quem-sao-os-adventistas/. Acesso em: 29 abr. 2020 .

RIFFEL, Juan; CHAIJ, Nicolás. "Podem trabalhar eficazmente". Revista Adventista, Santo André-SP, ano 50, n. 12, p. 3-4, Casa Publicadora Brasileira, dez. 1955.

SILVA, D. Pereira da. A bomba atômica espiritual. Revista Adventista, Santo André, v. 43, n. 11, p. 8, Casa Publicadora Brasileira, ago. 1948.

RODRIGUES, Aurelina P. Vitória. Revista Adventista, Santo André, v. 34, n. 11, p. 13, Casa Publicadora Brasileira, nov. 1939.

STRAHLE, John J. Com a rapidez do relâmpago. Revista Adventista, Santo André-SP, v. 35, n. 8, p. 2, Casa Publicadora Brasileira, ago. 1940.

SWARTOUT, Humberto. O conselheiro médico do lar. Santo André: Casa Publicadora Brasileira, 1942.

TSCHURTSCHENTHALER, Davi. O vencedor. Revista Adventista, Santo André-SP, v. 33, n. 8, p. 20, Casa Publicadora Brasileira, ago. 1939.

WHITE, Ellen G. A ciência do bom viver. Ellen G. White Estate, Inc. E-book, 2013.

\section{Referências}

ALI, Fatima. A arte de editar revistas. São Paulo: Companhia Editora Nacional, 2009. AUDTEC. Tabelas de valores de salário minimo de 1940 a 2020. Disponível em: http:// audtecgestao.com.br/capa.asp?infoid=1336. Acesso em: 30 set. 2020.

BELLOTTI, Karina Kosicki. "Um médico em forma de revista": aspectos constitutivos da revista adventista Vida e Saúde (1939-2019). Estudos de Religiáo, v. 34, n. 2, p. 489-519, maio-ago. 2020.

BELLOTTI, Karina Kosicki. Delas é o reino dos céus: mídia evangélica infantil e na cultura pós-moderna do Brasil (1950-2000). São Paulo: Fapesp/Annablume, 2010.

BORGES, Michelson. A chegada do Adventismo ao Brasil. Tatuí-SP: Casa Publicadora Brasileira, 2000.

BOYER, Paul S. From Tracts to Mass - Market Paperbacks: spreading the word via the printed page in America from the early national era to the present In: COHEN, C. L.; BOYER, P. S. (eds.). Religion and the culture of print in Modern America. Madison, WI: The University of Wisconsin Press, 2008. p. 14-38.

CAMPOS, Leonildo $S$. Os mapas, atores e números da diversidade religiosa cristá brasileira: católicos e evangélicos entre 1940 e 2007. Revista de Estudos da Religião - REVER, São 
“Alistando-SE No INVENCÍvel EXÉRCito DA PÁGINA IMPRESSA" - Cultura IMPRESSA ADVENTISTA No Brasil No SÉCULO XX

Karina Kosicki Bellotti

Paulo, ano 8, n. 4, p. 9-47, dezembro de 2008. Disponível em: https://www.pucsp.br/rever/ rv4_2008/t_campos.pdf. Acesso em: 6 maio 2020.

CERTEAU, Michel de. A invenção do cotidiano v.1 - Artes de fazer. 3. ed. Traduçáo de Ephraim Ferreira Alves. Petrópolis, RJ: Vozes, 1998. p. 259-273.

CHARTIER, Roger. (ed.). The Culture of Print: power and the uses of print in Early Modern Europe. Cambridge: Polity Press, 1989.

CHARTIER, Roger. Do códice ao monitor: a trajetória do escrito. Estudos Avançados, São Paulo, v. 8, n. 21, p. 185-199, 1994. Disponível em: https:/www.scielo.br/pdf/ea/ v8n21/12.pdf. Acesso em: 28 abr. 2020.

CHARTIER, Roger. O mundo como representação. In: CHARTIER, Roger. $\grave{A}$ beira da falésia. Porto Alegre: Editora UFRGS, 2002. p. 61-79.

CHARTIER, Roger. Textos, impressão, leitores. In: HUNT, L. (org.). Nova História Cultural. Tradução de Jefferson Luiz Camargo. Sáo Paulo: Martins Fontes, 1992. p. 211-238.

COHEN, Charles L.; BOYER, Paul S. (eds.). Religion and the culture of print in Modern America. Madison, WI: The University of Wisconsin Press, 2008.

DELUMEAU, Jean. Mil anos de felicidade: uma história do paraíso. São Paulo: Companhia das Letras, 1997.

GONÇALVES, Carlos Barros. Unum corpus sumus in Cristo? Iniciativas de fraternidade e cooperação protestante no Brasil (1888-1916). Curitiba, PR: Editora CRV, 2020.

KINTZ, Linda; LESAGE, Julia. (eds.). Media, culture and the religious right. Minneapolis, London: University of Minnesota Press, 1998.

LAND, Gary. Historical dictionary of the Seventh-day Adventists. Lanham, Maryland/ Toronto/Oxford: The Scarecrow Press, Inc., 2005.

MARRONI, Almir. Sementes e frutos. Revista Adventista. Tatuí-SP: Casa Publicadora Brasileira, ano 111, n. 1.309, p. 38-39, maio 2016.

MENDONÇA, Antonio Gouvêa. O Celeste porvir: a inserção do protestantismo no Brasil. São Paulo: ASTE, 1995.

MENDONÇA, Antonio Gouvêa; VELASQUES FILHO, Prócoro. Introdução ao Protestantismo. 2. ed. São Paulo: Loyola, 2002.

MORGAN, David. Protestants and Pictures: Religion, Visual Culture, and the Age of American Mass Production. New York: Oxford University Press, 1999.

OLIVEIRA FILHO, José Jeremias de. Formação histórica do movimento adventista. Estudos Avançados, v. 18, n. 52, p. 157-179, 2004.

OLIVEIRA FILHO, Sérgio William de Castro. "Candida": missōes e relações de gênero em um romance protestante no alvorecer do século XX. Tese (Doutorado em História). Campinas: Unicamp, 2018. 
RAMOS, Silvia (org.). Mídia e racismo. Rio de Janeiro: Pallas, 2002.

ROSA, Zita de Paula. O Tico-Tico: meio século de ação recreativa e pedagógica. Bragança Paulista: EDUSF, 2002.

SCHUNEMANN, Haller E. S. O tempo do fim: uma história social da Igreja Adventista do Sétimo Dia no Brasil. Tese (Doutorado em Ciências da Religião), Universidade Metodista de São Paulo, São Bernardo do Campo, 2002.

SMITH, Erin. What would Jesus read? Chapel Hill: The University of North Carolina Press, 2015.

VASCONCELOS, Micheline R. As Boas Novas pela palavra impressa: impressos e imprensa protestante no Brasil (1837-1930). Tese (Doutorado em História), Pontifícia Universidade Católica de São Paulo, 2010.

WILLIAMS, Raymond. Cultura e sociedade - 1780-1950. São Paulo: Companhia Editora Nacional, 1969. 